\title{
Learning Curve Based Sigma Level Determination in Interrupted Non-Production Processes
}

\author{
V. MolnAR, G. MetsZOSY \\ University of Miskolc, Faculty of Economics, Institute of Management Science, szvmv@uni-miskolc.hu
}

Abstract. The philosophy and methods of six sigma process development have been applied successfully since mid1980s, and the application of the six sigma concept in non-production processes has increased significantly in the last decade. In this paper processes that can be characterized by learning curves are modeled. The quality of such processes can be analyzed on the basis of the six sigma concept. In this paper two back office processes are analyzed. The processes are built up of simple repeated steps and incorporate some interruptions. The application of the model allows the calculation of the maximally permitted number of interruptions in the process if the preliminary determined norm is to be kept.

\section{Introduction}

The application of the six sigma process management concept goes back about thirty years. Since then numerous practical papers and professional reports have been published and the method has appeared to some extent in almost all industrial branches. Six sigma requires a high level of system orientation and complex organizational operation. This means that its adaptation and successful application depend on several factors, the center of which is human resources in most cases. Some powerful companies adapt six sigma and the advantages which can be observed in their achievements remain even long after the adaptation. Above this, six sigma affects mainly the achievement of employees and not the productivity of resources [1]. According to the six sigma approach the improvisation is relayed by the professional engineering approach, the guesses and subjective point of views by the objective data and the fictive results by money. And the application success of it depends on the personnel, their consistent work, cooperation and professionalism [2]. However, the interaction of work performance and motivation [3] can also be critical because 'better motivation of employees results in an efficient workforce and it eventually increases the overall efficiency of the organization' [4].

Unfortunately there are only a few research results that focus on successful application of the concept. Reports of empirical research are published now and then but the literature provides mainly only the success factors of single enterprises (case studies). Some examples of such success factors are summarized in Table 1 . The scientifically appropriate summary of success and the reliable generalization are topics requiring further work. It is important to highlight that the adaptation of not only six sigma but other modern process development concepts needs the support of several organizational factors, because the effect of globalization requires new ways of organizing work and 
new approaches to human resource management [5]. Beyond that, companies that are able to successfully manage changes have to react to the challenges of the information society and the turbulent market environments [6].

\begin{tabular}{|l|c|}
\hline \multicolumn{1}{|c|}{ Success factors } & Study \\
\hline $\begin{array}{l}\text { Involvement of employees; culture change; communication; infrastructure; training; } \\
\text { connecting six sigma clearly to enterprise's goals, customers, employees and suppliers; } \\
\text { understanding the methods; project managerial skills; adequate prioritization of projects. }\end{array}$ & [7], [8] \\
\hline $\begin{array}{l}\text { Managerial commitment and participation; corporate strategy built up to customer needs; } \\
\text { existing six sigma framework; project implementation and monitoring; investment in } \\
\text { resources; education framework; bonus system; collecting and analyzing available data; } \\
\text { reaching both short- and long-run goals; knowledge management system; project } \\
\text { formation on the basis of corporate strategy; cooperation and communication; proper } \\
\text { application of six sigma tools. }\end{array}$ & \\
\hline $\begin{array}{l}\text { Managerial support; exact connection to corporate strategy; exact quantification and } \\
\text { monitoring of results; clear financial results; efficient human resource allocation; proper } \\
\text { knowledge of six sigma concept. }\end{array}$ & [2] \\
\hline
\end{tabular}

Table 1. Critical success factors of six sigma adaptation

A number of reports have published on applications of six sigma since the mid-eighties. In the last decade the number of them has substantially increased. The published reports, case studies and application models can basically be analyzed by several aspects and this diversity sometimes makes a proper summary of the literature difficult. In one study, 82 papers dealing with the application of six sigma were analyzed to determine the share of application fields [10] (Fig. 1). The sample was obtained through the database ScienceDirect. It covered the period 2000-2015. Most of the publications were connected to industrial production (discrete or continuous) (42.7\%). Beyond that, the results of six sigma developments in the service industry (healthcare, education and other services) formed a significant share (23.3\%). The reason for the relatively high share of these areas is that the number of successful six sigma applications has increased significantly in the past years.

\begin{tabular}{|c|c|c|c|c|}
\hline Study & Year & Analyzed variable & $\begin{array}{c}\text { Current } \\
\text { value }\end{array}$ & $\begin{array}{c}\text { Value after } \\
\text { development }\end{array}$ \\
\hline [11] & 2005 & Average number of infections in a hospital per day & 11 & 1.7 \\
\hline [12] & 2011 & More than 10 minutes wait to surgery admission (\%) & 42 & 10 \\
\hline [13] & 2014 & Increasing $\sigma$-level & 3.31 & 4.5 \\
\hline \multirow{3}{*}[14]{} & \multirow{3}{*}{2015} & Employee satisfaction (\%) & 48 & 73 \\
\hline & & Waiting time (min) & 105 & 47 \\
\hline & & Lead time(min) & 135 & 66.5 \\
\hline [15] & 2017 & Increasing $\sigma$-level & 2.45 & 3.16 \\
\hline \multirow{2}{*}[16]{} & \multirow{2}{*}{2016} & Increasing $\sigma$-level (short-run) & 2.9 & 5.2 \\
\hline & & Increasing $\sigma$-level (long-run) & 1.4 & 3.7 \\
\hline
\end{tabular}

Table 2. Results of six sigma process development projects

One of the main rules of six sigma projects is that one should designate what has to be developed, how that can be quantified, and the concrete goal value of this factor. In Table 2 a short summary about development results of case-study type papers is given as an example. 


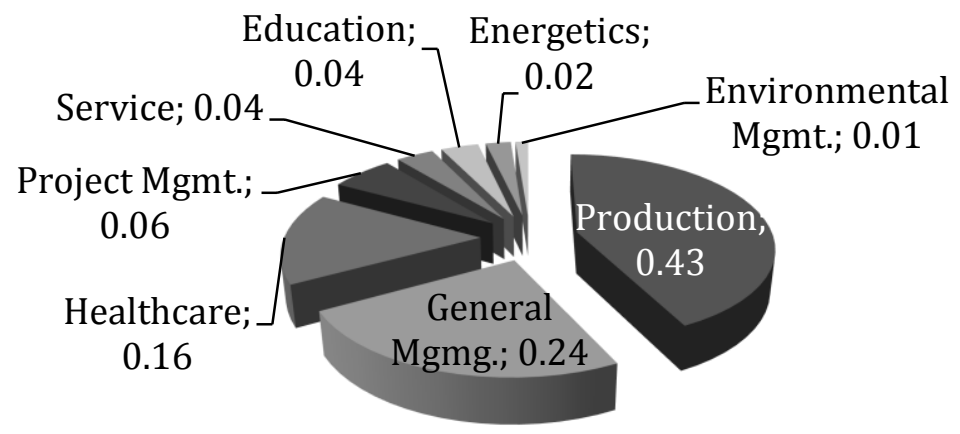

Figure 1. Distribution of application areas of six sigma [10]

\section{Application of six sigma in processes characterized by learning curve}

There are several methods for modeling production processes. From a morphological point of view most of the processes show a sequential form, i.e. they have determined start and finish points. Some characteristics of different, non-conventional processes are [17]:

- indefinite number and time interruptions,

- stochastic lead time,

- ad hoc content.

Some non-production processes can be characterized by one or by a combination of these. A back office worker receives their wage on the basis of the time spent in the office and not their achievement, in most cases. The tasks - ad hoc, regular or standard- performed in working hours can also be characterized by their lead time. Therefore, though with certain limitations, the costs of the work elements can easily be calculated [18]. The model introduced in this paper allows the determination of performance norms as well [19].

Similarly to standardized machine assembly processes, for example, several non-production processes can be characterized by learning curves. When performing a certain task, in the initial phase the time of the repeated steps is still relatively high and this time decreases with the increase of number of repetitions and eventually reaches a stabilized level. In case of the learning curve defined in this manner, the time values higher than the stabilized level are times of learning or 'attunement'. This phase is natural in several types of work. However, if the process is interrupted by shorter or longer periods, the process becomes one that incorporates several phases characterized by several learning curves. Due to the learning phases, the time of all the repeated steps will higher compared to the same process without interruptions. From this point of view all the time values over the stabilization level of the learning curves located after the first interruption can be considered as waste. This waste can be reduced or eliminated by the elimination of interruptions, which can be realized by rational work organization. 


\section{Mathematical model}

To introduce the model, let a process be characterized by an indefinite number of interruptions and stochastic activity time. A typical learning curve can be described by an exponential function. In Fig. 2 the process is demonstrated. The process contains $m$ work phases, therefore $m$ learning curves. There are $m-1$ interruptions in the whole process. The last steps directly before the interruptions are designated by $n, x$ is the number of repetitions and $t$ is the realization time of a step. The average of all the steps of the whole process is $t_{\Sigma}$ and the deviation is $s_{\Sigma}$. It is supposed that the stabilized values of all the learning curves are equal.

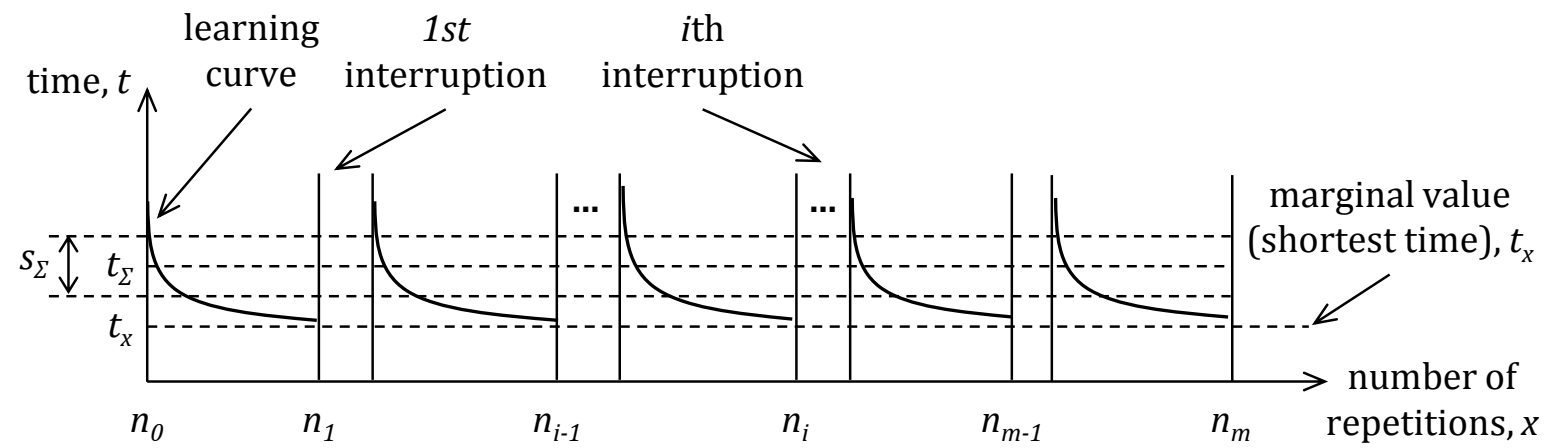

Figure 2. Modeling of process incorporating interruptions with learning curves

Notations of Fig. 3 are applied to describe the process located directly before the ith interruption. In this phase $k_{i}-n_{i}$ is the section in which only stochastic fluctuation can be found (further decrease of time is not possible in the given circumstances). This means that in the continuous approach the learning curve holds for the marginal value (shortest time). These values of the curve are located in a sufficiently small $\delta$ environment. Value $t_{i}{ }^{*}$ designates the $i$ th repeated step. The $k_{i}$ is determined by the appropriately chosen $\delta$. The average time of the repeated steps before $k_{i}$ is $t_{i}^{* *}$. The time loss resulted from the initial learning is designated by $V_{i}$.

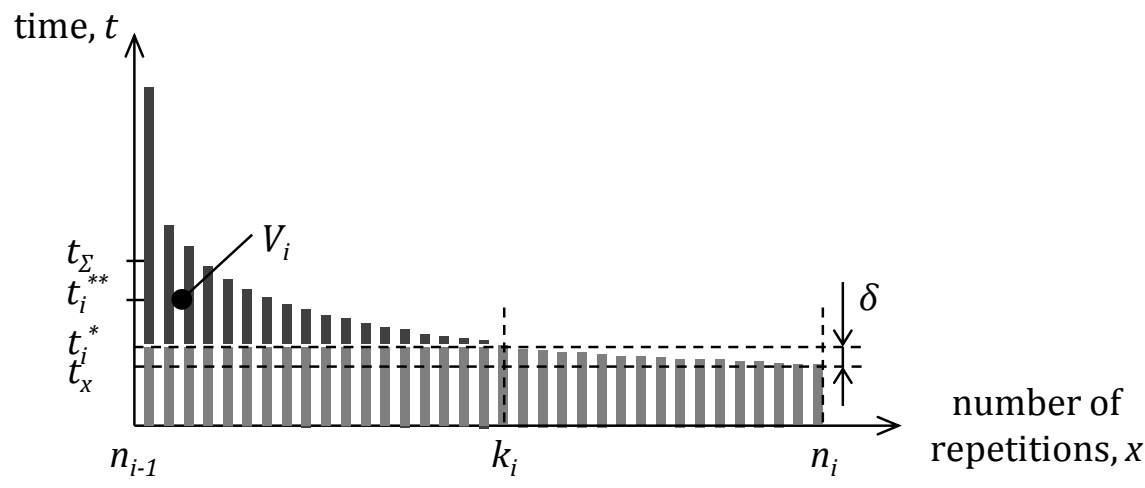

Figure 3. Model of the phase before the first interruption

Applying the notations of Fig. 3, the calculation of time loss can be constructed. This loss and the marginal value $\left(t^{*}\right)$ of the stabilization section $\left(k_{i}-n_{i}\right)$ for the $i$ th phase can be calculated by Eqs. (1-2). 
Total time loss of the process can be calculated by Eq. (3). Average time and empirical deviation of the repeated steps can be calculated by Eq. (4) and Eq. (5), respectively.

$$
\begin{gathered}
V_{i}=\sum_{x=n_{i-1}}^{k_{i}} t_{x}-\left(k_{i}-n_{i-1}\right) t_{i}^{*} \\
t_{i}^{*}=\frac{1}{n_{i}-k_{i}} \sum_{x=k_{i}}^{n_{i}} t_{x} \\
V=\sum_{j=1}^{m} V_{j} \\
t_{\Sigma}=\frac{1}{m} \sum_{x=n_{0}}^{n_{m}} t_{x} \\
s_{\Sigma}=\sqrt{\frac{\sum\left(t_{x}-t_{\Sigma}\right)^{2}}{n_{m}-1}}
\end{gathered}
$$

Let the process be developed by simple work organization methods where the interruptions and therefore the relearning times are eliminated. Applying the notations of Fig. 2, the developed process is demonstrated in Fig. 4. The area above the curve ( $T$ - total time of work) demonstrates the state after process development and can be calculated by Eq. (6).

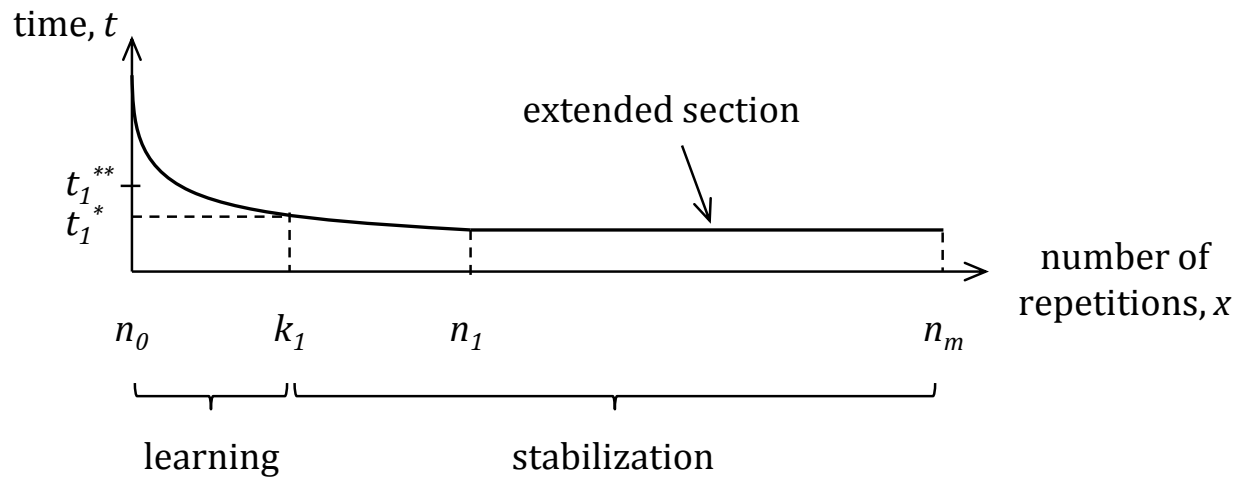

Figure 4. Process model after elimination of interruptions

$$
T=\sum_{x=n_{0}}^{k_{1}} t_{x}+\left(n_{m}-k_{1}\right) t_{d}^{*}
$$

To determine the sigma level of the process calculation of some deviation value is necessary. It can be supposed that the deviation of the section between $k_{i}$ and $n_{i}$ (stabilization section) equals that of the rest of the process. But the number of considered values is different, therefore the square summing of $s_{k 1 n 1}$ (Eq.(7)) deviation of the $k_{1}-n_{1}$ section is necessary for the whole $k_{1}-n_{m}$ section. The modified $s_{m}$ empirical deviation (Eq.(8)) refers to a section that generally is not necessarily an integer multiple value of the section $k_{1}-n_{1}$. 


$$
\begin{gathered}
s_{k 1 n 1}=\sqrt{\frac{\sum\left(t_{x}-t_{d}^{*}\right)^{2}}{n_{1}-k_{1}-1}} \\
s_{m}=\sqrt{\frac{n_{m}-k_{1}}{n_{1}-k_{1}}\left(s_{k 1 n 1}\right)^{2}}
\end{gathered}
$$

To describe the process formally the section $n_{0}-k_{1}$ has to be considered as well. The deviation of this section can be calculated by Eq. (9). The empirical deviation of the whole process (learning and stabilization sections) can be determined by Eq. (10).

To interpret sigma level let $p$ [\%] be defined. The meaning of this parameter is that what percent is allowed for exceeding the planned time of work ( $T$ ). Then the acceptance range of the whole work time can be designated by $L$ (Eq. (11)). Sigma level can be calculated by Eq. (12).

$$
\begin{gathered}
s_{n 0 k 1}=\sqrt{\frac{\sum\left(t_{x}-t_{d}^{* *}\right)^{2}}{k_{1}-n_{0}-1}} \\
s=\sqrt{\left(s_{n 0 k 1}\right)^{2}+s_{m}^{2}} \\
L:\left[T ;\left(1+\frac{p}{100}\right) T\right] \\
l=\frac{p T}{100 s}
\end{gathered}
$$

In this method, due to the learning curve the distribution of time values is lognormal. Its density function is asymmetric; the minimum value of the probability variable is the marginal value (stabilization section). The method allows the amount of time loss to be determined, similarly to the determination of scrap rates of manufacturing processes. If previously determined learning curve parameters are available, determining the sigma level can provide information about the maximum number of interruptions, which is connected to the acceptable extra time. Application of the method can be necessary if the analyzed process contains only the extra times of relearning. Elimination of other problems and waste generally has to come before that of the relearning waste, because they tend to be on a larger scale, e.g. in case of problems like raw material availability or non-time-related errors of work or scrap.

\section{Application example 1 - class schedule entry of a university department}

In our analysis the steps of class schedule completion were measured course by course. In this analysis we measured time spent for each step in the process of entering data into an electronic system for a subject to be offered during the semester. The person who was traced is experienced in this activity. These steps incorporate the following elementary tasks: choosing the lecturer's name from a list; 
checking possibilities of combining classes; registering the time load of lectures and seminars. Two very similar processes were analyzed. The first is the above activities connected to the class schedule for full-time students. In this process there were some interruptions. The second process was the same for the schedule for part-time students, in which there was no interruption. In the first analysis interruptions were intentionally built into the process. The first interruption lasted 3 hours and the second 1 hour. In both processes the processing time of 53 subjects were measured. The measured data of the two processes are summarized in Table 3. The higher values of learning sections can be observed easily.

To calculate the parameters of the model first the $k$ values (number of the repeated step which can be considered as the starting point of stabilization) were designated. In the three phases of the interrupted process these are 10,9 and 5, respectively. The calculated values for the phases $\left(t_{i}{ }^{*}, s\right)$, the $t_{\Sigma}$ and $s_{\Sigma}$ values connecting to the whole process, the modified $s_{m}$ deviation and the $s$ deviation of the process are summarized in Table 4.

\begin{tabular}{|c|c|c|c|c|c|c|c|c|c|c|c|c|c|c|c|c|c|}
\hline \multicolumn{4}{|c|}{$\begin{array}{c}1^{\text {st }} \text { process } \\
1^{\text {st }} \text { phase }\end{array}$} & \multicolumn{4}{|c|}{$\begin{array}{l}1^{\text {st }} \text { process } \\
2^{\text {nd }} \text { phase }\end{array}$} & \multicolumn{2}{|c|}{$\begin{array}{c}1^{\text {st }} \text { proc. } \\
3^{\text {rd }} \text { ph. }\end{array}$} & \multicolumn{8}{|c|}{$2^{\text {nd }}$ process } \\
\hline 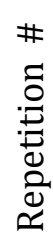 & $\begin{array}{l}\bar{n} \\
\stackrel{\Xi}{\Xi} \\
\dot{\xi}\end{array}$ & 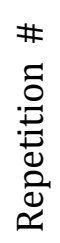 & $\underset{\Xi}{\tilde{g}}$ & 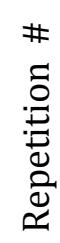 & $\frac{\tilde{n}}{\tilde{\Xi}}$ & 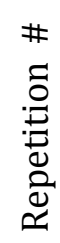 & $\begin{array}{l}\bar{n} \\
\stackrel{\Xi}{\Xi} \\
\dot{E}\end{array}$ & 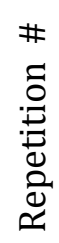 & $\underset{\Xi}{\Phi}$ & 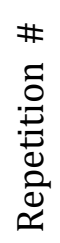 & $\begin{array}{l}\bar{n} \\
\stackrel{v}{\Xi} \\
\dot{E}\end{array}$ & 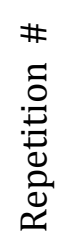 & $\begin{array}{l}\bar{n} \\
\stackrel{\Xi}{\Xi} \\
\dot{E}\end{array}$ & 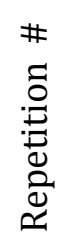 & 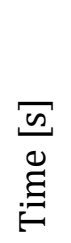 & 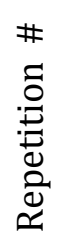 & 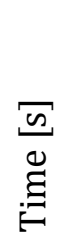 \\
\hline 1 & 74 & 15 & 50 & 1 & 81 & 15 & 51 & 1 & 72 & 1 & 75 & 15 & 52 & 29 & 52 & 43 & 48 \\
\hline 2 & \begin{tabular}{|l|l|}
70 \\
\end{tabular} & 16 & 45 & 2 & 74 & 16 & 54 & 2 & 70 & 2 & 70 & 16 & 50 & 30 & 48 & 44 & 49 \\
\hline 3 & 61 & 17 & 49 & 3 & 71 & 17 & 47 & 3 & 59 & 3 & 71 & 17 & 53 & 31 & 43 & 45 & 47 \\
\hline 4 & 53 & 18 & 48 & 4 & 72 & 18 & 50 & 4 & 52 & 4 & 62 & 18 & 45 & 32 & 48 & 46 & 49 \\
\hline 5 & 46 & & & 5 & 63 & 19 & 44 & 5 & 55 & 5 & 55 & 19 & 50 & 33 & 49 & 47 & 43 \\
\hline 6 & 52 & & & 6 & 60 & 20 & 45 & 6 & 46 & 6 & 53 & 20 & 52 & 34 & 49 & 48 & 45 \\
\hline 7 & 54 & & & 7 & 52 & 21 & 50 & 7 & 45 & 7 & 53 & 21 & 49 & 35 & 51 & 49 & 48 \\
\hline 8 & 51 & & & 8 & 58 & 22 & 51 & 8 & 47 & 8 & 51 & 22 & 48 & 36 & 45 & 50 & 47 \\
\hline 9 & 47 & & & 9 & 51 & & & 9 & 52 & 9 & 49 & 23 & 49 & 37 & 50 & 51 & 48 \\
\hline 10 & 50 & & & 10 & 47 & & & 10 & 52 & 10 & 48 & 24 & 49 & 38 & 48 & 52 & 50 \\
\hline 11 & 51 & & & 11 & 53 & & & 11 & 46 & 11 & 52 & 25 & 51 & 39 & 49 & 53 & 44 \\
\hline 12 & 50 & & & 12 & 45 & & & 12 & 49 & 12 & 52 & 26 & 50 & 40 & 47 & & \\
\hline 13 & 48 & & & 13 & 54 & & & 13 & 52 & 13 & 52 & 27 & 47 & 41 & 50 & & \\
\hline 14 & 49 & & & 14 & 52 & & & & & 14 & 51 & 28 & 47 & 42 & 49 & & \\
\hline
\end{tabular}

Table 3. Time measurement data of time schedule completion process [17]

The average times of the stabilization sections are between 48.89 and $49.57 \mathrm{sec}$ and the deviations are between 1.76 and 3.54 sec. These values can be considered similar. The averages prove the supposition that with a similar physical and mental load similar values can be measured in the 
stabilization sections. The reason for the relatively higher differences among the deviation values is the difference in the number of repetitions.

\begin{tabular}{|c|c|c|c|}
\hline Parameter & Value & Parameter & Value \\
\hline$t_{1}{ }^{*}\left(k_{1}-n_{1}\right)$ & $48.89 \mathrm{~s}$ & $t_{\Sigma}\left(n_{0}-n_{3}\right)$ & $54.15 \mathrm{~s}$ \\
\hline$S_{k 1 n 1}$ & $1.76 \mathrm{~s}$ & $s_{\Sigma}\left(n_{0}-n_{3}\right)$ & $9.09 \mathrm{~s}$ \\
\hline$S_{n 0 k 1}$ & $9.86 \mathrm{~s}$ & $s_{m}$ & $3.9 \mathrm{~s}$ \\
\hline$t_{2}{ }^{*}\left(k_{2}-n_{2}\right)$ & $49.57 \mathrm{~s}$ & $S$ & $10.61 \mathrm{~s}$ \\
\hline$s_{k 2 n 2}$ & $3.39 \mathrm{~s}$ & & \\
\hline$t_{3}{ }^{*}\left(k_{3}-n_{3}\right)$ & $49.33 \mathrm{~s}$ & & \\
\hline$S_{k 3 n 3}$ & $3.54 \mathrm{~s}$ & & \\
\hline
\end{tabular}

Table 4. Calculated values of the first measurement (full-time class schedule)

The reason for the relatively high value of the calculated $s$ is that the first 10 points of the first learning curve show a great fluctuation. The total time of the interrupted process is $2870 \mathrm{sec}$. After the process development (elimination of interruptions) the value of $T$ identifies to what extent the whole process time can be decreased. Substituting the corresponding parameters in Eq. (6), this value is $2659 \mathrm{sec}$, which is a $7.4 \%$ reduction in time. If a $1 \%$ limit is available for exceeding the planned $T$ time of work, the sigma level of the process without interruptions is 2.51 (Eq. (12) is applied).

In the next step let us consider the second process, which contains no interruptions (the part-time class schedule). The total time of the process is $2682 \mathrm{sec}$, which is $6.5 \%$ lower than that of the first process. In this process the average time of the stabilized section (starts at the $15^{\text {th }}$ repeated step) is $48.42 \mathrm{sec}$ and the deviation is 2.38 . Considering the $1 \%$ limit again, these values lead to a 11.26 sigma level, which is 4.49-fold of the first process which included interruptions. The meaning of this is that although the lead time did not decrease radically, the stability of the process shows a relatively significant improvement.

\section{Application example 2 - registering data from invoices}

In the second example the time needed to register data contained in invoices in an electronic system is analysed. We examine whether a certain extent difference experienced in the parameters of the phases limits the application of the model. Times of repeated steps of a process were measured. There were two interruptions in the process ( 1 and 3 hours), so the process contained three phases. The time values are summarized in Fig. 5. Registration of 21 invoices was measured.

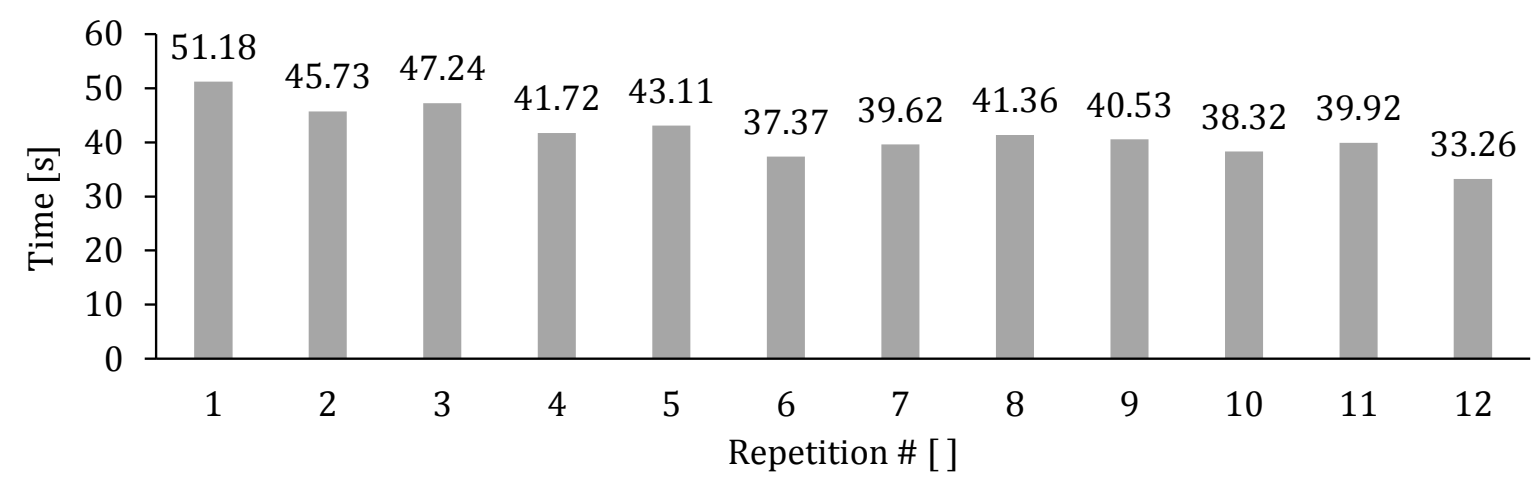

a) 


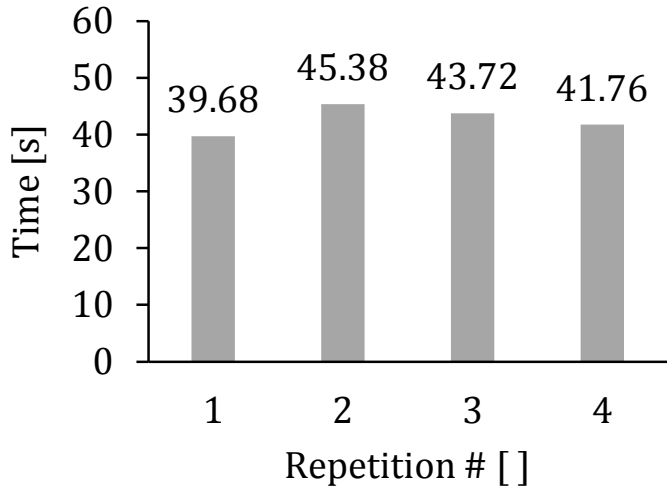

b)

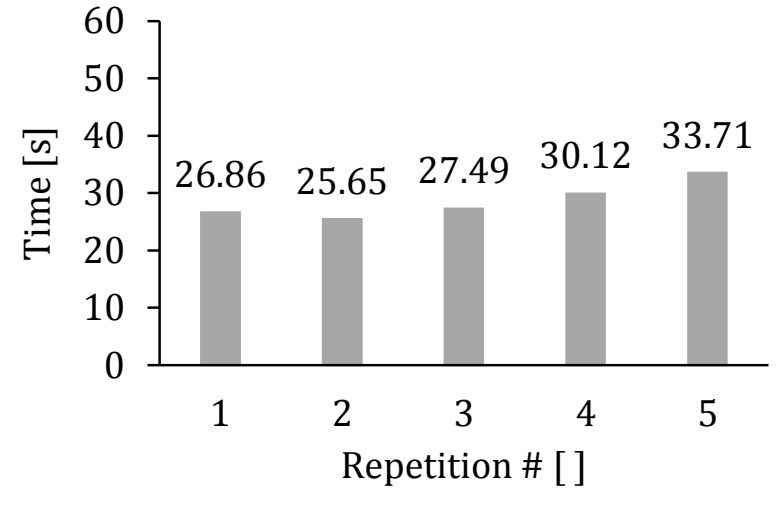

c)

Figure 5. Time measurement data of invoice registration process

On the basis of these data the calculated values of the model parameters are summarized in Table 5 . The $k$ values of the three phases are 5, 2 and 3, respectively. In this case we were unable to collect data for an uninterrupted period of entering data, so no comparison can be made. The total time of the original process is $813.83 \mathrm{sec}$. Eliminating the interruptions the calculated value of $T$ is $856 \mathrm{sec}$. It can be observed that the average values of the second and third phases, with relatively low deviation values, greatly differ from each other.

\begin{tabular}{|c|c|c|c|}
\hline Parameter & Value & Parameter & Value \\
\hline$t_{1}{ }^{*}\left(k_{1}-n_{1}\right)$ & $39.19 \mathrm{~s}$ & $t_{\Sigma}\left(n_{0}-n_{3}\right)$ & $38.75 \mathrm{~s}$ \\
\hline$s_{k 1 n 1}$ & $2.97 \mathrm{~s}$ & $s_{\Sigma}\left(n_{0}-n_{3}\right)$ & $6.95 \mathrm{~s}$ \\
\hline$s_{n 0 k 1}$ & $3.91 \mathrm{~s}$ & $s_{m}$ & $4.33 \mathrm{~s}$ \\
\hline$t_{2}{ }^{*}\left(k_{2}-n_{2}\right)$ & $43.62 \mathrm{~s}$ & $s$ & $5.84 \mathrm{~s}$ \\
\hline$s_{k 2 n 2}$ & $1.81 \mathrm{~s}$ & \\
\cline { 1 - 2 }$t_{3}{ }^{*}\left(k_{3}-n_{3}\right)$ & $30.44 \mathrm{~s}$ & \\
\hline$s_{k 3 n 3}$ & $3.12 \mathrm{~s}$ & \\
\hline
\end{tabular}

The extent of this difference means that development on the basis of the introduced model is no longer realistic because the $T$ value whose improvement was desired happens to have a higher value than the original one. This type of discrepancy can be experienced if the work intensity of an analyzed person is altered to a great extent after an interruption. To eliminate this problem, it is necessary to register more data. A similar distorted case could be experienced if the work of different persons were modeled. In this example it can be observed that in the third phase a fatigue section appears, i.e. the time values after a certain number of repetition start increasing slowly.

\section{Summary}

The aim of the simple mathematical model introduced in this paper is to give advice to decisionmakers interested in six sigma process development by quantified data. The model can help to determine process parameters that connect to the time values of repeated simple work steps. In the model exceeding a preliminary determined norm is considered as an error. In the model the sigma level is considered by lognormal distribution of time values of the exponential learning curve. The 
sigma level provides information about the stability of the process. A case study was used to show the possibilities for application of the model. A second case study highlighted an important instance when the result of the model is distorted. It is supposed in the model that after each interruption a certain level of relearning starts in the same process. However, the model does not yet account for at the fact that at the end of long processes the time of repeated steps can increase, due to the load on the worker and worker fatigue.

\section{Acknowledgement}

This research was supported by the project no. EFOP-3.6.2-16-2017-00007, titled 'Aspects on the development of intelligent, sustainable and inclusive society: social, technological, innovation networks in employment and digital economy'. The project has been supported by the European Union, co-financed by the European Social Fund and the budget of Hungary.

\section{References}

[1] S. M. Shafer - S. B. Moeller (2012) The Effects of Six Sigma on Corporate Performance: An Empirical Investigation. Journal of Operations Management 30, 521-532.

[2] L. Simanova (2015) Specific Proposal of the Application and Implementation Six Sigma in Selected Processes of the Furniture Manufacturing. Procedia Economics and Finance 34, 268-275.

[3] A. Nemeti - A. Matko (2018) Egy hazai vállalat szervezeti magatartásának vizsgálata, különös tekintettel a motivációra (En: Analysis of Organizational Behaviour of a Domestic Enterprise with Special Regard to Motivation). International Journal of Engineering and Management Sciences 3(3), 206-216.

[4] A. Matko - T. Takacs (2017) Examination of the Relationship between Organizational Culture and Performance. International Review of Applied Science and Engineering 8(1), 99-105.

[5] K. Dajnoki - M. Heder (2017) „Új szelek fújnak” - a HR válasza a globalizáció és a változás kihívásaira (En: „New Winds Blow” - The Answer of HR for the Challenges of Globalization and the Change), Hadtudomány 27, 84-93.

[6] A. Matko - D. Krisztina - Z. Baksi - T. Takacs (2015) Framework of Change Management. In: C. Baban - F. S. Blaga - A. V. Pele - M. T. Pop - A. Rus - R. C. Tarca (eds.): Proceedings of the Annual Session of Scientific Papers, 14(24), Publishing House, 113-118.

[7] Y. H. Kwak - F. T. Anbari (2006) Benefits, Obstacles, and Future of Six Sigma Approach, Technovation 26, 2006, 708-715.

[8] A. Brun (2011) Critical Success Factors of Six Sigma Implementations in Italian Companies. International Journal of Production Economics 131, 158-164.

[9] Y. C. Ho - O. C. Chang - W. B. Wang (2008) An Empirical Study of Key Success Factors for Six Sigma Green Belt Projects at an Asian MRO Company. Journal of Air Transport Management 14, 263 269.

[10] V. Molnar - A. Kerchner (2016) A Lean menedzsment Alkalmazási lehetôségei a közszférában (En: Application Potentials of Lean Management in the Public Sector). Conference proceedings of MTEKMR, 425-432. 
[11] H. L. Frankel - W. B. Crede - J. E. Topal - S. A. Roumanis - M. W. Devlin - A. B. Foley (2015) Use of Corporate Six Sigma Performance-Improvement Strategies to Reduce Incidence of Catheter-Related Bloodstream Infections in a Surgical ICU. Journal of American College of Surgeons 201, 349-359.

[12] R. R. Cima - M. J. Brown - J. R. Hebl - R. Moore - J. C. Rogers - A. Kollengode - G. J. Amstutz - C. A. Weisbrod - B. J. Narr - C. Deschamps (2011) Use of Lean and Six Sigma Methodology to Improve Operating Room Efficiency in a High-Volume Tertiary-Care Academic Medical Center. Journal of American College of Surgeons 213, 83-94.

[13] K. Srinivasan - S. Muthu - N. K. Prasad - G. Satheesh (2014) Reduction of Paint Line Defects in Shock Absorber through Six Sigma DMAIC Phases, Procedia Engineering 97, 1755-1764.

[14] S. J. Gleich - M. E. Nemergut - A. A. Stans - D. T. Haile - S. A. Feigal - A. L. Heinrich - C. L. Bosley J. W. Ward - S. Tripathi (2015) Lean Six Sigma Handoff Process between Operating Room and Pediatric ICU: Improvement in Patient Safety, Efficiency and Effectiveness. Critical Care 19(1), 523.

[15] M. Ortiz-Barrios - P. Lopez-Meza - G. Jimenez (2017) Applying Computer Simulation Modelling to Minimizing Appointment Lead-Time in Elderly Outpatient Clinics: A Case Study. In: S. Ochoa - P. Singh - J. Bravo (eds.): Ubiquitous Computing and Ambient Intelligence, UCAmI, 323-329.

[16] A. Pugna - S. Potra - R. Negrea - S. Miclea - M. Mocan (2016) A Refined Quality Attribute Classification Model for New Product and Service Strategic Design. Procedia Computer Science 91, 296-305.

[17] V. Molnar (2016) Nem termelési folyamatok kontrollja six sigma megközelítésben (En: Control of Non-Production Processes in Six Sigma Approach). Controller Info 4(2), 37-44.

[18] Z. Musinszki (2014) Cost to be a cost? Cost in the management accounting. In: Z. Zeman (eds.): Controller Info Studies, 134-138.

[19] M. Veres Somosi - G. Kocziszky (2018) Performance-based management of public utility organizations. In: Z. Zeman - M. Robert (eds.): Controller Info Studies II, 2018, 146-152. 